\title{
Development of word lists in Telugu for assessing speech recognition threshold: alternative forms to existing word lists
}

\author{
S. B. Rathna Kumar ${ }^{1 *}$, Madhu Sudharshan Reddy. B ${ }^{2}$, Sale Kranthi ${ }^{3}$
}

\author{
${ }^{1}$ Department of Audiology, Ali Yavar Jung National Institute for the Hearing Handicapped, Mumbai, India \\ ${ }^{2}$ Department of Prevention of Communication Disorder (POCD), All India Institute of Speech and Hearing, Mysore, \\ India \\ ${ }^{3}$ Department of Speech Language Pathology, Ali Yavar Jung National Institute for the Hearing Handicapped, \\ Secunderabad, India
}

Received: 24 May 2016

Revised: 23 June 2016

Accepted: 25 June 2016

*Correspondence:

Dr. S. B. Rathna Kumar,

E-mail: sarathna@yahoo.co.in

Copyright: (C) the author(s), publisher and licensee Medip Academy. This is an open-access article distributed under the terms of the Creative Commons Attribution Non-Commercial License, which permits unrestricted non-commercial use, distribution, and reproduction in any medium, provided the original work is properly cited.

\begin{abstract}
Background: The present study aimed to develop word lists in Telugu for assessing speech recognition threshold which might serve as equivalent and alternative forms to the existing word lists.

Methods: A total of two word lists were developed using compound words with each list consisting of 25 words. Equivalence analysis and performance-intensity function testing was carried out using two word lists on a total of 75 native speakers of Telugu who were equally divided into three groups.

Results: The results revealed that there was no statistically significant difference $(\mathrm{p}>0.05)$ in the speech recognition performance between three groups for each word list, and between two word lists for each group. Hence, the two word lists developed were found to be equally difficult for all the groups and can be used interchangeably. The performance-intensity (PI) function curve showed semi-linear function, and the subjects reached the beginning of the plateau at 3 dBSL where they reached more than $90 \%$ speech recognition score for two word lists, and reached $100 \%$ speech recognition score at $6 \mathrm{dBSL}$. The 50\% speech recognition score which corresponds to SRT was obtained at less than 1.5 dBSL for two word lists suggesting good agreement between PTA and SRT.

Conclusions: The findings of the study are similar to the findings of existing word lists in Telugu. Thus the developed word lists in the present study can be considered equivalent and alternative forms to existing word lists in Telugu.
\end{abstract}

Keywords: Speech recognition threshold, Compound words, Equivalence analysis, Performance-intensity function testing

\section{INTRODUCTION}

Pure-tone audiometry is an important part of many specialized procedures for testing auditory function as well as for evaluating the performance of hearing aids and other forms of aural rehabilitation devices. Pure-tone audiometry involves an easy administration with uncomplicated response task. The identification of the stimulus by an individual presumes a relatively simple neural apparatus and the response in general raising the hand, is not a complex task. ${ }^{1}$ In addition pure-tone audiometry provides valuable information about the degree, type and configuration of hearing loss, and also facilitates in making decisions for the need for further tests or medical interventions. In spite of having such advantages, pure-tone audiometry provides only a partial idea about the auditory status because it does not give any 
direct information about one's ability to hear and understand speech. ${ }^{2}$

Speech is a meaningful and important signal which is very closely associated with day-to-day functioning of the human being, and also provides an idea about human's ability to understand everyday social communication. 'Speech perception' is the process of transformation of an acoustic signal transmitted from a speaker to an intended communicative message heard by a listener, for whom the perception of speech seems to be effortless and automatic. ${ }^{4}$ Thus speech perception forms the basis for communicative exchange and also plays an important role in the acquisition of language and communication. $^{3}$

The ability to understand speech must be considered as an important measurable aspect of the functions of human auditory system. ${ }^{5}$ The process of testing the patient with speech stimuli in order to find out how he/she hears and understands speech is known as speech audiometry. ${ }^{2}$ There are two common speech audiometric tests used for diagnostic purpose in the clinical audiology. The first is "speech recognition threshold" (SRT), i.e. the lowest intensity level where a person can recognize the speech stimuli for $50 \%$ of time, as measured by pure-tone audiometry. The second is "speech recognition score" (SRS), i.e. the maximum speech recognition score obtained in percentage for speech material presented at comfortable supra-threshold level.

The SRT testing has the following clinical functions: 1) serves as a measure for corroborating pure-tone thresholds, 2) serves as a reference point for deciding the appropriate presentation levels for the administration of supra-threshold speech recognition test, 3 ) determines the needs and performance of hearing aids, 4) ascertains the need for aural rehabilitation and monitor the progress in the management process, 5) determines hearing sensitivity of young children and others who are difficult to test. $^{2}$

The stimuli used to obtain SRT are spondaic words often called as spondees. Spondees are disyllabic words which can be produced with equal stress or emphasis on both the syllables (e.g. 'football', 'playground', 'doormat', 'sunset' etc) making them to easily discriminate and guess with high degree of accuracy in obtaining reliable and valid SRT. With reference to English, Hudgins developed 42-word spondee recorded test at the Harvard Psychoacoustic Laboratory (PAL). ${ }^{6}$ Subsequently, the original spondee materials have been improved by Hirshe at Central Institute for the Deaf (CID) by reducing the list to the 36 most familiar spondees considered to be most homogenous with respect to their audibility. ${ }^{7}$ In addition, American Speech and Hearing Association recommended a streamlined list with 15 spondees considered to be highly homogenous with respect to audibility based on the research by Young. ${ }^{8,9}$ Similarly, American Speech and Hearing Association recommended a list with 20 spondees which can be represented by picture that are suitable for testing young children based on the research by Frank. 8,10

Speech audiometry has become a fundamental tool in audiological assessment, and SRT testing must be evaluated routinely using valid and reliable clinical assessment procedures appropriate for different population in their native language. With regard to the history of materials for assessing SRT, standardized materials have been developed and used extensively in English and other languages. Unlike English, Indian languages do not contain true spondees. However, several attempts have been made in Indian languages to develop different kinds of materials by altering stress and force on words to mimic spondee configuration for assessing SRT, such as paired words in Hindi, disyllabic words in Malayalam, spondees in Indian English, paired words in Kannada, disyllabic words in Tamil, disyllabic words in Gujarati, polysyllabic words in Manipuri, paired words in Bengali etc. as published by Kacker and Basavaraj. ${ }^{11,12}$

Telugu, a South Central Dravidian language, is one of the 23 scheduled languages recognized by the Constitution of India. Telugu has the $3^{\text {rd }}$ largest number of native speakers in India and $13^{\text {th }}$ largest number of native speakers worldwide. It is the official language of Andhra Pradesh and Telangana, southern states of India, and the mother tongue of the majority of people of the two states. With reference to Telugu, Padmaja developed two lists of disyllabic words with each list consisting of 25 words, and Sreedhar developed two lists of paired words with each list consisting of 25 words for assessing SRT. ${ }^{11,13}$ However, it was reported that a strong SRT-PTA agreement could be obtained only with paired words developed by Sreedhar. ${ }^{11}$

The two word lists developed in Telugu by Sreedhar may be adequate for routine hearing and hearing aid evaluation. ${ }^{11}$ However, more than one form of the same test is usually provided because more than one administration is almost always necessary under experimental and clinical conditions. The limited number of word lists upon multiple administrations of same items will affect the test findings due to familiarization, practice and learning effects. In addition, there is a rapid and continuous evolution in hearing device technology with new signal processing strategies with various features. When these features in a hearing device have to be evaluated and compared on a number of conditions, more number of such word lists are mandatory. ${ }^{14}$ Hence, several equivalent and alternative forms of the tests are needed so that subject's performance is not a reflection of their ability to remember the speech stimuli, rather, their performance in the recognition of the speech stimuli. ${ }^{15}$ The present study aimed to develop word lists with compound words for assessing SRT which might serve as equivalent and alternative forms to the existing word lists. 


\section{METHODS}

The study was conducted in the following two phases: 1) Development of word lists in Telugu for assessing SRT and 2) Formal study for equivalence analysis and performance-intensity function testing.

\section{Development of word lists}

The development of word lists in Telugu for assessing SRT was conducted in the following five phases: 1) collection of compound words in Telugu, 2) familiarity assessment of collected words, 3) validation of most familiar words, 4) pilot study to assess homogeneity with respect to audibility of words, and 5) construction of final word lists.

\section{Collection of compound words in Telugu}

The compound words in Telugu were collected from various sources like general books, story books, periodicals, newspapers, magazines, and spontaneous speech. These words were subjected to familiarity assessment.

\section{Familiarity assessment}

The collected words were assessed for familiarity in order to ensure that these are known to native speakers of Telugu and are commonly used by people belonging to Andhra Pradesh and Telangana, southern states of India. A total of 150 subjects who are native speakers of Telugu in the age range between 18 and 35 years from Coastal Andhra and Rayalaseema regions of Andhra Pradesh, and Telangana were included in order to assess familiarity of words. The subjects were further equally subdivided into three groups based on the above mentioned regions. A three-point rating scale was used for familiarity rating such as most familiar, familiar and unfamiliar. The subjects were explained about the ratings such as: 1) most familiar: a word should be rated as 'most familiar' if the subject knows the meaning of that word and he/she uses the same word to express in a day-to-day basis, 2) familiar: a word should be rated as 'familiar' if the subject knows the meaning of that word but he/she uses an alternative word to express in the daily activities, 3) unfamiliar: a word should be rated as 'unfamiliar' if the subject is not aware of it.

The responses of the subjects were scored based on threepoint rating scale, i.e. the words which were rated as most-familiar, familiar and unfamiliar were assigned a score of 2, 1 and 0 respectively. Based on the subjects' ratings, a word-wise total score was calculated and converted into percentage. The words with $90 \%$ score and more were selected for each group and further assessed for homogeneity across groups. These words were considered for further assessment.

\section{Validation of most familiar and commonly used words}

Content validity was carried out in order to review how the essential words can attribute to the test measures. The most familiar and commonly used words were given to five experts working in the field of Speech Language Pathology, Audiology, and Linguistics in order to carry out the content validation. The experts were informed about the purpose of the test procedure and asked to respond whether the words selected would fulfil the purpose. Their responses were elicited under the categories of "use the word" and "do not use the word". A word-wise validation was carried out by each expert. The words which were agreed by each expert were selected and listed separately. These words were further assessed for homogeneity across the responses of the experts. The words which were commonly agreed by all the experts were listed separately and subjected to further analysis.

Pilot study to assess homogeneity with respect to audibility of words

A pilot study was carried out in order to identify words that are homogenous with respect to their audibility. This study was intended to identify the words which would be recognized by a group of normal hearing subjects at an intensity level where it is expected to be recognized correctly so that they can be considered homogenous with respect to their audibility. It is generally expected that normal hearing subjects obtain SRT within $5 \mathrm{dBSL}$ with reference to PTA. ${ }^{16}$ Hence, we have carried out speech recognition testing at $5 \mathrm{dBSL}$ with reference to PTA on normal hearing subjects.

\section{Procedure}

A total of 75 subjects in the age range between 18 and 35 years with normal hearing and no speech disorders belonging to Costal Andhra and Rayalaseema regions of Andhra Pradesh, and Telangana were selected as subjects. They were further equally subdivided into three groups based on the above mentioned regions. All the tests were conducted in sound treated room where the ambient noise levels were within permissible limits. The audiological evaluations including otoscopic examination, pure-tone audiometry and tympanometry were conducted to ensure that suitable subjects with normal hearing were selected. The speech recognition testing was carried out on each subject of three groups. The words were presented through digital diagnostic audiometer with TDH 39 transducers using monitored live voice, ensuring that the deflection of the vu meter was zero. A distance of 6-9 inches was maintained between the microphone and the mouth of the tester. Each subject was given the following instructions in Telugu: "You will now listen to some words presented one after another through headphones. Listen carefully to those words and when you hear a word, please repeat it in a loud voice". All the words were presented at the 
presentation level of $5 \mathrm{dBSL}$ with reference to PTA. If the subject felt tired during the test, a short break was given.

A word-wise analysis was done and the words which were correctly repeated by the subjects were listed separately for each group. These words were further assessed for homogeneity across the groups. The words which were repeated correctly by the subjects of three groups were listed separately and considered homogenous with respect to their audibility.

\section{Construction of word lists}

The words which were homogenous with respect to their audibility served as foundation for development word lists. From the existing pool of words, a total of two word lists with each word list consisting of 25 words were constructed to assess SRT in Telugu (see Appendix). Each word list was randomized thrice to form a total of 6 word lists. Each randomized word list was spoken by an adult female native speaker of Telugu and recorded in a sound treated room. The inter stimulus interval between the two words was set to 5 seconds. A calibration tone of $1 \mathrm{KHz}$ was inserted before beginning of the word list to adjust the vu meter at zero. The word lists were then copied onto an audio compact disc using a compact disc writer.

\section{Formal study}

A formal study was carried out in order to assess equivalence analysis of word lists and performanceintensity function testing of word lists.

\section{Participants}

A total of 75 subjects in the age range between 18 and 35 years with normal hearing and no speech disorders served as subjects. All the subjects were native speakers of Telugu belonging to Coastal Andhra and Rayalaseema regions of Andhra Pradesh, and Telangana. The subjects were further equally divided into three groups based on the above mentioned regions.

\section{Procedure}

All the tests were conducted in a sound treated room where the ambient noise levels were within permissible limits. The audiometric assessments including otoscopic examination, pure-tone audiometry and tympanometry were conducted to ensure that suitable subjects with normal hearing were selected. The speech recognition score (SRS) testing was carried out on each subject with two word lists. The stimulus was played through a CD player, which was routed through digital diagnostic audiometer and delivered through the TDH 39 headphones.The stimulus was presented at $0 \mathrm{dBSL}, 3$ $\mathrm{dBSL}$ and $6 \mathrm{dBSL}$ with reference to PTA. At each presentation level a different randomized list was used and the order of list was also changed. All the subjects were tested monaurally with two word lists and ear selection was done randomly. An open-set response in the form of an oral response was obtained. Each subject was given following instructions in Telugu "you will listen to the words presented one after another through headphones. Listen carefully and when you hear a word repeat the word in a loud voice". If the subject felt tired during the test, a short break was given. Initially ten practice items were presented in order to familiarize the subjects with the test procedure. The responses of the subjects were marked as either 0 or 1 . Each correct response was given a score of 1 and an incorrect response was given a score of 0 . The raw score was then converted to percentage which is known as SRS for compound words.

\section{Equivalence analysis of word lists}

Equivalence analysis of word lists was carried out in order to ensure that the two word lists are equally difficult for three groups and can be used interchangeably. The SRS was calculated for each subject for two word lists separately at each presentation level. The groups' mean SRS obtained by three groups for two word lists were calculated and used for assessing equivalence analysis.

\section{Performance-Intensity function (PI) testing}

The groups' mean SRS for each word list at different presentation levels were used to obtain the PI function curve for each word list. PI function curve is a graphical representation of groups' mean SRS (Y-axis) as a function of intensity level of stimulus, i.e. $0 \mathrm{dBSL}, 3$ $\mathrm{dBSL}$ and $6 \mathrm{dBSL}$ (X-axis) with reference to PTA. The SRT will be drawn from this PI function curve, i.e. the level (on the X-axis) at which the groups' mean SRS reaches $50 \%$ (on the $\mathrm{Y}$-axis) will be considered as SRT for particular word list.

\section{Statistical analysis}

The mean and standard deviation values of SRS obtained by three groups of subjects for two word lists were subjected to one-way ANOVA in order to find out significant difference between groups for each word list, and between word lists for each group. Curve estimation and regression analysis were carried out in order to find out linearity function of the PI function curve and the level at which $50 \%$ SRS was obtained.

\section{RESULTS}

\section{Equivalence analysis of words lists}

The results indicated that with an increase in the presentation level, there was a corresponding increase in the mean SRS for two word lists in three groups (Table 1). The data were subjected to one-way ANOVA in order 
to find out significant difference in mean SRS obtained by each group between three presentation levels $(0 \mathrm{dBSL}$, $3 \mathrm{dBSL}$ and $6 \mathrm{dBSL}$ ) for two word lists. The results revealed that there was a statistically significant difference between and within presentation levels [F (2) $=3931.45, \mathrm{p}<0.05]$. Hence the data were further subjected to LSD post-hoc analysis in order to find out significant difference in mean SRS between presentation levels. The results revealed that there was a statistically significant difference $(\mathrm{p}<0.01)$ in mean SRS between 0 dBSL and 3 $\mathrm{dBSL}$ and $0 \mathrm{dBSL}$ and $6 \mathrm{dBSL}$ in each group for both the lists. However, there was no statically significant difference $(>0.05)$ between $3 \mathrm{dBSL}$ and $6 \mathrm{dBSL}$ in each group for both the lists (Table 2).
In addition, the data were further subjected to one-way ANOVA in order to find out significant difference in mean SRS between two word lists for each group, and between three groups for each word list at each presentation level. The results revealed that there was no statistically significant difference $(p>0.05)$ in mean SRS of each group between two word lists, and there was no statistically significant difference $(p>0.5)$ in the mean SRS for each word list between three groups at all the presentation levels (Table 3). Hence, it can be concluded that the two word lists developed were equally difficult for all the groups and can be used interchangeably.

Table 1: Mean and SD values of SIS obtained by three groups for two lists.

\begin{tabular}{|cccccccc|}
\hline $\begin{array}{c}\text { Word } \\
\text { List }\end{array}$ & Presentation Level & \multicolumn{2}{c}{ Group I } & \multicolumn{2}{c}{ Group II } & \multicolumn{2}{c|}{ Group III } \\
\hline List 1 & Mean & SD & Mean & SD & Mean & SD \\
\hline & dB SL & 21.12 & 10.67 & 21.28 & 10.56 & 20.96 & 10.78 \\
\hline & 3 dB SL & 98.40 & 02.30 & 98.08 & 02.03 & 98.24 & 02.02 \\
\hline List 2 & 6 dB SL & 100.00 & 00.00 & 100.00 & 00.00 & 100.00 & 00.00 \\
\hline & $0 \mathrm{~dB} \mathrm{SL}$ & 20.84 & 10.82 & 21.28 & 10.56 & 21.12 & 10.67 \\
\hline & 3 dB SL & 98.24 & 02.33 & 98.40 & 02.00 & 98.08 & 02.03 \\
\hline & $6 \mathrm{~dB} \mathrm{SL}$ & 100.00 & 00.00 & 100.00 & 00.00 & 100.00 & 00.00 \\
\hline
\end{tabular}

Table 2: Significant values of SIS obtained for two lists at different presentation levels on LSD post-hoc analysis.

\begin{tabular}{|ccccc|}
\hline Word List & $\begin{array}{c}\text { Presentation Level } \\
\text { (Reference to PTA) }\end{array}$ & Mean difference & Standard error & $\begin{array}{c}\text { Statistical } \\
\text { significance }\end{array}$ \\
\hline \multirow{3}{*}{ List 1 } & 0 dBSL vs. 3 dBSL & -76.96000 & 1.01383 & $\mathrm{p}<0.01$ \\
\hline \multirow{2}{*}{ List 2 } & O dBSL vs. 6 dBSL & -78.72000 & 1.01383 & $\mathrm{p}<0.01$ \\
\hline & 3 dBSL vs. 6 dBSL & -1.76000 & 1.01383 & $\mathrm{p}>0.05$ \\
\hline & 0 dBSL vs. 3 dBSL & -77.17333 & 1.01256 & $\mathrm{p}<0.01$ \\
\hline & 0 dBSL vs. 6 dBSL & -78.88000 & 1.01256 & $\mathrm{p}<0.01$ \\
\hline & 3 dBSL vs. 6 dBSL & -1.70667 & 1.01256 & $\mathrm{p}>0.05$ \\
\hline
\end{tabular}

Table 3: Significant values of SIS obtained for two lists at each presentation level for all the groups on ANOVA analysis.

\section{Variables}

List 1 (0 dBSL) vs. List 2 (0 dBSL)

List 1 (3 dBSL) vs. List 2 ( 3 dBSL)

List 1 (6 dBSL) vs. List 2 (6 dBSL)
Statistical significance

$p>0.05$

$p>0.05$

$p>0.05$

\section{Performance-Intensity (PI) function testing}

The PI function curve is a graphical representation of the groups' mean SRS obtained for each word list as a function of presentation level, i.e. $0 \mathrm{dBSL}, 3 \mathrm{dBSL}$ and 6 dBSL with reference to PTA. It was observed that with an increase in the presentation level, there was a corresponding increase in the mean SRS for two word lists (Table 1). There was a statistically significant difference $(\mathrm{p}<0.05)$ in groups' mean SRS between 0 $\mathrm{dBSL}$ and $3 \mathrm{dBSL}$, and $0 \mathrm{dBSL}$ and $6 \mathrm{dBSL}$ presentation levels for both the lists. However, there was no statistically significant difference $(p>0.05)$ between in groups' mean SRS between $3 \mathrm{dBSL}$ and $6 \mathrm{dBSL}$ presentation levels for both the lists (Table 2). The PI function curve showed semi-linear function with narrow standard deviation values for mid- and high- presentation levels, while broad standard deviation values for low presentation levels. The subjects in the present study 

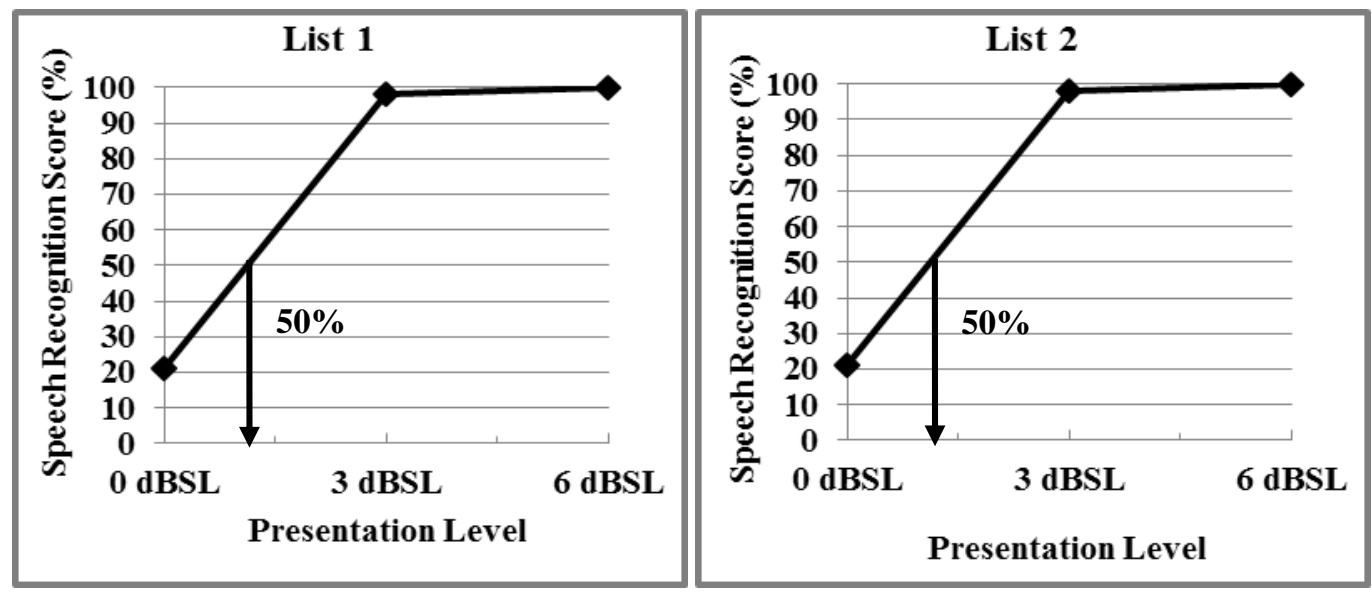

Figure 1: Groups' mean performance-intensity function curve for two lists.

reached the beginning of the plateau at $3 \mathrm{dBSL}$ where they reached more than $90 \%$ SRS for two word lists, and reached $100 \%$ SRS at $6 \mathrm{dBSL}$. The $50 \%$ SRS which corresponds to SRT was obtained at less than 1.5 dBSL with reference to PTA for two word lists (Figure 1).

\section{DISCUSSION}

The SRT testing is an important part of speech audiometry, and SRT testing must be evaluated routinely using appropriate materials for different population in their native language. With reference to Telugu Sreedhar developed two lists of paired words with each list consisting of 25 words for assessing SRT. ${ }^{11}$ These word lists were reported to be having strong SRT-PTA agreement, and found to be adequate for routine audiological evaluation. However, more than one form of the same test is usually needed as more than one administration is almost always necessary under multiple clinical and experimental conditions, e.g. we routinely test the speech recognition of each ear separately, assessing the performance of different hearing aids, different listening conditions etc. There is high possibility of practice and learning effect that occurs as a function of both the use of multiple administrations as well as limited alternative forms of the same test. Hence, there is a need to have alternative forms of the tests so that subject's performance is not a reflection of their ability to remember the speech stimuli, rather, their recognition performance of the stimuli. ${ }^{15}$

The present study developed two word lists in Telugu with each list consisting of 25 compound words for assessing SRT. While the physiological functioning of an individuals' auditory system is undoubtedly a major determinant of his or her hearing status, the linguistic and cultural differences should not be disregarded as they can affect every stage of audiological assessment. The liability and validity of speech recognition testing can be influenced by factors such as word familiarity, words in common use, type of stimulus and homogeneity with respect to audibility of words.
It is a well-established fact that the intelligibility of speech stimuli increases when the subject's level of familiarity with the test words is greater. ${ }^{17}$ Telugu is spoken in Andhra Pradesh and Telangana, southern states of India, and official language of both the states. Although, the mother tongue of majority of people of two states is Telugu, some of the frequently occurring words in one region may not be familiar to people belonging to other regions due to variations in regional dialects. ${ }^{18}$ Therefore, the differences in the frequency of occurrence of a test word in different dialects might affect the speech recognition performance of representatives of different dialects. Hence, we have carried out familiarity assessment on native speakers of Telugu belonging to different regions (Coastal Andhra and Rayalaseema regions of Andhra Pradesh, and Telangana) in order to ensure that the test words are familiar and known to native speakers of Telugu. The next step after familiarity assessment was selection of words that are commonly used by native speakers of Telugu belonging to different regions. Therefore, the words rated as 'most familiar' were listed for each group of native speakers of Telugu separately and these words were further assessed for homogeneity across the groups in order to ensure that selected words were known to and were commonly used by them. In addition, these words were further subjected to content validity in order to review how essential these words can attribute to the test measures.

Another important consideration in the development of word lists for assessing SRT is the type of stimuli used. The stimuli used to obtain SRT are spondaic words often called as spondees. Spondees are disyllabic words with two meaningful components (two monosyllabic words), e.g. 'football' ('foot' and 'ball'), 'playground' ('play' and 'ground'), 'sunset' ('sun' and 'set') etc. which can be produced with equal stress or emphasis on both the components (monosyllabic words). This makes spondees more redundant, and relatively easy to discriminate and guess them with a high degree of accuracy. Hence, once the threshold for spondees has been reached it does not take much intensity before all the words can be correctly recognised. 
Unlike English, Indian languages do not contain true spondees. However, several attempts have been made by several investigators to develop different kinds of materials for assessing SRT (e.g. disyllabic words, paired words, reduplicated words) by altering the stress and force on words to mimic spondee configuration. ${ }^{11}$ Similarly, we have developed word lists using 'compound words' in the present study. A compound word is a combination of two or more words that function as a single unit of meaning. The present study considered only open and closed compound words which are made up with two words. This is because, the components of open and closed compound words can occur in isolation, i.e. independently in the language, and there is a possibility for descriptive explanation or paraphrasing, e.g. /cettabutța/ (/cetta/ 'dust' and /butța/ 'bin'), /vānapāmu/ (/vāna/ 'rain' and /pāmu/ 'snake', /patṭucĪra/ (/patṭu/ 'silk' and /cĪra/ 'sari'), /talanoppi/ (/tala/ 'head' and /noppi/ 'ache', /gālivāna/ (/gāli/ 'wind' and /vāna/ 'rain') etc. Hence it is expected that these words can also be produced with altered stress and emphasis to mimic the spondee configuration in order to help the listener to easily discriminate and guess them with high degree of accuracy. We have not considered set compounds, because, in set compounds, one or both of the components have no meaning in the language and descriptive explanation or paraphrasing is not possible. Hence they might not provide much redundant information to guess the words with high degree of accuracy.

In summary spondees are used as stimuli for assessing SRT in English often called as spondee threshold. This is because spondees are disyllabic words which can be produced with equal stress on both syllables making them redundant to guess more accurately. Thus SRT is the lowest intensity level at which an individual can recognize and repeat $50 \%$ of spondees, provided the language contains spondees. Unlike English, Indian languages do not contain true spondees. However, words such as paired words, reduplicated words, compound words etc. can be used as stimuli by altering the stress and force on these words to mimic spondee configuration in such languages. Hence it can be concluded that "speech recognition threshold is the lowest intensity level at which an individual can recognize and repeat 50\% of test words which are more redundant".

Homogeneity of test words with respect to their audibility is a crucial consideration because it is necessary to enhance the precision with which the SRT can be established, and ensure that the number of responses increases rapidly with a relatively small rise in presentation levels. ${ }^{1}$ This means that with small increase in intensity, the scores of SRT climb rapidly resulting in short test duration and less listener fatigue. We have carried out a pilot study in order to ensure that the test words are homogenous with respect to their audibility. A pilot study is a miniature version of a study used to test the validity of the collected words prior to the actual study. This study is intended to identify the words which would be recognized by a group of normal hearing subjects at an intensity level where it is expected to be recognized correctly so that they can be considered homogenous with respect to their audibility.

It is generally expected that SRT is obtained within 5 dBSL with reference to PTA and suggests a good agreement between SRT and PTA. ${ }^{16}$ Hence, in the pilot study we have presented the collected words (based on familiarity assessment and expert validation) at $5 \mathrm{dBSL}$ with reference to PTA on normal hearing subjects. The words which were recognised by the subjects of each group were listed separately and assessed for homogeneity across three groups. The words which were repeated by all the subjects of three groups were considered to be homogenous with respect to their audibility and served as foundation for developing word lists. Thus a total of two word lists with each list consisting of 25 words were developed from the existing pool of words.

Any measurement used to assess one's behavioural performance should be subjected to standards in order to ensure that the measure accurately reflects the behaviour of interest. Reliability is a psychometric principle that plays an important role in the development of any speech audiometric materials. It refers to the extent to which the findings are repeatable by the same individual using the same test of a particular attribute, by the same individual using different tests of the attribute, or by different individuals using the same test of the attribute without the interference of error. ${ }^{15}$ In the present study, the equivalence analysis of two word lists was carried out in order to check the reliability of developed word lists. This type of reliability helps to ensure that the two word lists must be equally difficult so that the subjects' speech recognition performance obtained on one word list is similar to the performance of the same group of subjects on other word list. On the other hand, to ensure that the subjects' of different groups obtain similar speech recognition performance on same word list. It was found that there was no statistically significant difference in SRS between two word lists for each group, and no significant difference between three groups for each word list. Hence, the two word lists were found to be reliable, equally difficult, and can be used interchangeably for any group of subjects in clinical practice.

The extent to which a test instrument appears to measure what it is supposed to measure constitutes validity. The degree of validity is measured as the correlation between test instrument scores and criterion-related variables, and generally, the higher the correlation, the greater the degree of validity. ${ }^{15}$ In the present study, the PI function testing was carried out which involved the calculation of groups' mean SRS for compound words as a function of $0 \mathrm{dBSL}, 3 \mathrm{dBSL}$ and $6 \mathrm{dBSL}$ presentation levels with reference to PTA. The results revealed a narrow standard deviation for mid and high presentation levels and broad 
standard deviation for low presentation level. This is expected because at low presentation levels, the phonemic cues become less consistent in terms of audibility and hence, becomes more difficult to guess the words with high accuracy. On the other hand, as the presentation level increases, the important phonetic cues become more consistent in terms of audibility. Moreover, the nature of compound words, i.e. having two meaningful components and homogeneity with respect to their audibility might have enabled them more redundant, relatively easy to discriminate and guess, and recognise with a high degree of accuracy. Hence, once the SRT has been reached it did not take much intensity to reach $100 \%$ recognition of test words. In general SRTs obtained within $5 \mathrm{dBSL}$ with reference to PTA are considered to be valid thresholds and suggests strong SRT-PTA agreement. An unexplained discrepancy of more than 6 dBSL between SRT and PTA must be questioned and referred for further evaluations to resolve the discrepancy. In the present study the subjects obtained SRT at less than 1.5 dBSL with reference to PTA for both the lists which are falling well within the expected levels. The findings of the study are similar to the findings of existing word lists in Telugu. ${ }^{11}$ Thus the developed word lists in the present study can be considered equivalent and alternative forms to existing word lists in Telugu.

\section{CONCLUSION}

The present study developed two word lists in Telugu for assessing speech recognition threshold of adults. Each word list consists of 25 compound words. Equivalence analysis of two word lists revealed that there was no statistically significant difference in speech recognition performance between two word lists for each group, and no significant difference between three groups for each word list. The developed word lists were found to be showing good PTA-SRT agreement. The findings of the study are similar to the findings of existing word lists in Telugu. Hence they can be considered as equivalent and alternative forms to existing word lists in Telugu.

\section{ACKNOWLEDGMENTS}

Authors would like to thank all the subjects who have participated in the study. We acknowledge Dr. S. G. R. Prakash and Dr. S. Santhi Prakash, AYJNIHH for their continued support. Special thanks to Shri. B. Shivaprasad, Shravya Speech and Hearing Centre, Hyderabad for his support in completing this work.

Funding: No funding sources Conflict of interest: None declared

Ethical approval: Not required

\section{REFERENCES}

1. Schill HA. Thresholds for Speech: In Katz J, ed. Handbook of clinical audiology. $3^{\text {rd }}$ ed. Baltimore: Williams \& Wilkins; 1985:224-34.

2. Gelfand SA. Essentials of audiology. $2^{\text {nd }}$ ed. New York: Thieme Medical Publishers; 2007.

3. Nandurkar A, Mukundan G, Gore G. Speech perception assessment among audiologists in India: a preliminary survey. Int $\mathbf{J}$ Speech Lang Pathol. Audiol.. 2015;3:52-65.

4. Gierut JA, Pisoni DB. Speech perception: In Lass N, McReynolds L, Northern J, Yoder D, eds. Handbook of speech-language pathology and audiology. Philadelphia: B. C.Decker; 1988:264-87.

5. Penrod JP. Speech discrimination testing: In Katz J, ed. Handbook of clinical audiology. $3^{\text {rd }}$ ed. Baltimore: Williams \& Wilkins; 1985: 235-255.

6. Hudgins C, Hawkins J, Karlin J, Stevens S. The development of recorded auditory tests for measuring hearing loss for speech. Laryngoscope. 1947;57:57-89.

7. Hirsh IJ, Davis H, Silverman SR, Reynolds EG, Eldert E, Benson RW. Development of materials for speech audiometry. J Speech Hear Disor. 1952;17:321-37.

8. ASHA. Determining Threshold Level for Speech [Guidelines]. Available from www.asha.org/policy. 1988. Accessed 10 June 2016.

9. Young LL, Dudley B, Gunter MD. Thresholds and psychometric functions of the individual spondaic words. J Speech Hear Res. 1982;25:586-93.

10. Frank T. Clinical significance of the relative intelligibility of pictorially represented spondee words. Ear and Hearing. 1980;1:46-9.

11. Sreedhar JS, Venkatesh L, Nagaraja MN, Srinivasan P. Development and evaluation of paired words for testing of speech recognition threshold in Telugu: a preliminary report. J of Ind Speech Hear Assoc. 2011;25(2):128-36.

12. Kacker SK, Basavaraj V. Indian Speech, Language and Hearing Tests: The ISHA battery-1990. Mysore: Indian Speech and Hearing Association; 1990.

13. Padmaja. Spondees in Telugu for testing of SRT. In: Kacker SK, Basavaraj V. (Eds), Indian Speech, Language and Hearing Tests: The ISHA battery1990. Mysore: Indian Speech and Hearing Association; 1990.

14. Manjula P, Antony J, Kumar KSS, Geetha C. Development of phonemically balanced word lists for adults in the Kannada language. J Hear Sci. 2015;5(1):22-30.

15. Mendel LL, Danhauer JL. Audiologic evaluation and management and speech perception assessment. San Diego: Singular Publishing Company; 1997.

16. Chaiklin JB. The relation among three selected auditory speech thresholds. J Speech Hear Res. 1959;2:237-43. 
17. Luce PA, Pisoni DB. Recognizing spoken words: the neighbourhood activation model. Ear and Hearing. 1998;19:1-36.

18. Kumar SBR, Mohanty P. Speech recognition performance by adults: a proposal for a battery for Telugu. Th Prac in Lang Stud. 2012;2(2):193-204.

19. Wang S, Mannell R, Newall P, Zhang H, Han D. Development and evaluation of Mandarin disyllabic materials for speech audiometry in China. In J Aud. 2007;46(12):719-31.

Cite this article as: Kumar SBR, Reddy MB, Kranthi S. Development of word lists in Telugu for assessing speech recognition threshold: alternative forms to existing word lists. Int J Otorhinolaryngol Head Neck Surg 2016;2:14756. 


\section{Appendix}

Word lists in Telugu for assessing speech recognition threshold.

\begin{tabular}{|c|c|c|c|}
\hline \multicolumn{2}{|c|}{ List 1} & \multicolumn{2}{|c|}{ List 2} \\
\hline చెత్త - బుట్ట & cetta - buțta & అగ్గి - పుల్ల & aggi - pulla \\
\hline బెండ - కాయ & benḍa - kāya & పూల - దండ & pūla - danḍa \\
\hline కత్తి - పీట & katti - pīṭa & కళ్ళ - జోడు & ka!̣̣a - jōḍu \\
\hline కుక్క - పిల్ల & kukka - pilla & మేక - పోతు & mēka - pōtu \\
\hline మంచి - నీళ్ళు & maňci - nī!̣u & సొట్ట - బిందె & soțta - binde \\
\hline పూల - గంప & pūla - gampa & పంచె - కట్టు & paňce - katṭu \\
\hline సొట్ట - బుగ్గ & soțța - bugga & గాలి - వాన & gāli - wāna \\
\hline వాన - పాము & wāna - pāmu & పుట్టు - మచ్చ & putțu - macca \\
\hline దున్న - పోతు & dunna - pōtu & పాల - బుగ్గ & pāla - bugga \\
\hline నాటు - మందు & nātu - mandu & చింత - పండు & cinta - panḍu \\
\hline ముద్ద - పప్పు & mudda - pappu & గోరు - ముద్ద & gōru - mudda \\
\hline బండ - రాయి & banḍa - rāyi & కోడి - పుంజు & kōḍi - punju \\
\hline మల్లె - మొగ్గ & malle - mogga & కంది - పప్పు & kandi - pappu \\
\hline బంతి - పూలు & banti - pūlu & తోడు - దొంగ & tōḍu - doňga \\
\hline కోడి - గుడ్డు & kōḍi - guḍḍu & పాము - పుట్ట & pamu - putța \\
\hline ఆడ - పిల్ల & āḍa - pilla & కంటి - చూపు & kanți - cūpu \\
\hline పచ్చి - గడ్డి & pacci - gaḍ̣̣i & పచ్చ - బొట్టు & pacca - boțțu \\
\hline లేత - కొమ్మ & leta - komma & తల - నొప్పి & tala - noppi \\
\hline వేప - చెట్టు & wēpa - cețṭu & ముళ్ళ - కంప & muḷa - kampa \\
\hline ముళ్ళ - పంది & mul!a - pandi & గుండు - సూది & gunḍu - sūdi \\
\hline నిప్పు - రవ్వ & nippu - rawwa & పిచ్చి - కుక్క & picci - kukka \\
\hline జామ - కాయ & jāma - kāya & వాలు - జడ & wālu - jaḍa \\
\hline బంక - మట్టి & banka - mațți & మట్టి - కుండ & mațți - kunḍa \\
\hline గాజు - ముక్క & gāju - mukka & మల్లె - పువ్వు & malle - puwwu \\
\hline పట్టు - చీర & pațtu - cīra & నిమ్మ - కాయ & nimma - kāya \\
\hline
\end{tabular}

